\title{
COMPUTATIONAL ETHNOMUSICOLOGY: A STUDY ON FLAMENCO AND ARAB-ANDALUSIAN VOCAL MUSIC
}

\author{
Nadine Kroher, Emilia Gómez, Mohamed Sordo \\ Music Technology Group, Universitat Pompeu \\ Fabra \\ $\{$ name $\}$. surname $\}$ dupf .edu
}

\author{
Jose-Miguel Díaz-Báñez, Joaquín Mora \\ Universidad de Sevilla \\ jbanez@us.es jmora@us.es
}

\author{
Francisco Gómez-Martín \\ Universidad Politécnica de Madrid \\ fmartin@eui.upm.es
}

\author{
Amin Chaachoo \\ Asmir Center Tetouan \\ chaachooamin@gmail.com
}

\section{INTRODUCTION}

This interdisciplinary case study focuses on two well-established music traditions, flamenco and Arab-Andalusian music with special focus on the melodic aspects of the singing voice. We apply a hybrid methodology combining a traditional musicological analysis with music information retrieval techniques. Focusing on two representative pieces, a flamenco martinete and an Arab-Andalusian inshad, we illustrate commonalities and divergences among these traditions, and evidence on how existing technologies allows us to formalize expert's knowledge and complement traditional analysis methodologies by discovering relationships that might otherwise have been unnoticed.

\section{BACKGROUND}

\subsection{Flamenco}

Flamenco is an oral music tradition with roots as diverse as the cultural influences of its area of origin, Andalusia, a region in southern Spain. Over the centuries, the area and, of course, its music have been influenced by the ancient Tartessian culture as well as Phoenician and Roman colonizations, notwithstanding later settlements by the Visigoths, the Arabs, the Jews, the Christians, and to a large extent gipsies, who decisively contributed to shape its form as we know it today (Blas-Vega \& Ríos-Ruiz, 1988; Navarro \& Ropero, 1995).

Flamenco music germinated and nourished mainly from the singing tradition (Gamboa, 2005). Accordingly, the role of the singer soon became dominant and fundamental. The flamenco singing voice can be characterized as unstable in pitch, timbre and dynamics (Merchán Higuera, 2008). Melodic movements are composed of conjunct degrees and performances include spontaneous complex, microtonal ornamentations and melisma (Mora et al., 2010).

\subsection{Arab-andalusian music}

The Arab-Andalusian music tradition can be traced back to the 12th century in Al-Andalus, to the muslims andchristians living in the Moorish Spain (Chaachoo, 2011) and is the result of many influences, including Middle-East Arabic classical music, Hispanic music traditions of the Iberian peninsula, and other classical traditions such as the Gregorian and Byzantine ones. The Andalusian tradition is maintained in quite a few north african regions (Poché, 1995; Guettat, 2000) mainly in Morocco, Algeria, and Tunisia.

Andalusian music is organized around the concept of nawba (Poché, 1995; Guettat, 2000), a collection of melodies belonging to the same a melodic mode, which defines not only the pitch content but is also linked to specific emotions or states of mind and is consequently associated with certain social occasions. Furthermore a mode is defined by its pitch range (tessitura), a tonal center around which the melody gravitates, important scale degrees which provide the mode's characteristic flavor and a set of melodic cells, known as centones. The singing voice being the key element, Andalusian music is characterized by the use of sung poems (san'as) (Cortés García, 2003), taken from Arabic classical poetry. As in the case of flamenco, Andalusian music tradition has been preserved and kept alive as an oral tradition.

\section{MUSICOLOGICAL ANALYSIS}

\subsection{1. The flamenco martinete}

The martinete is a traditional monophonic flamenco singing style characterized by a common melodic skeleton, slow tempo, solemn performance, free rhythmic interpretation and a large amount of melismatic ornamentation. In the present study we provide a detailed analysis of a martinete performance by the renowned singer Tomás Pavón, treating musical form, characteristic melodic movements, underlying tonality and the use of ornamentation. We furthermore introduce different concepts of symbolic representation and analysis schemes. 

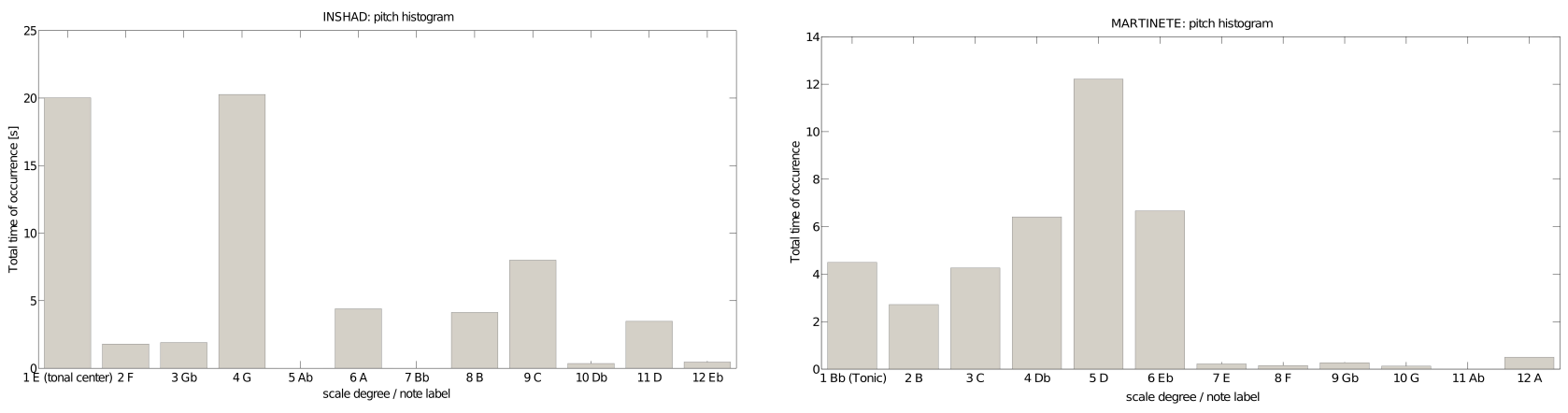

Figure 1. Pitch histograms of the inshád (left) and the martinete (right) performance.

tions.

\subsection{The Arab-andalusian inshád}

The inshád is a sung poem of two verses. Forming part of the Arab-Andalusian musical heritage, the melodic progression is based on set motives which are spontaneously ornamented (Chaachoo, 2011). We analyze a performance by singer Zohra Abbetiw in the Al-Sika mode. After giving an overview of the general characterstics of the mode, we discuss rhythmic interpretation, the tonal importance of the scale degrees, formal aspects and the use of ornamentation in the performance under study.

\section{COMPUTATIONAL ANALYSIS}

Manual analysis is complemented by the extraction and interpretation of melody-related features on various abstraction levels. We extract automatically-computed fundamental frequency and energy envelopes and analyze their fine-structure regarding the use of ornamentation, frequency and volume vibrato as well as melisma. In a next step, an automatic transcription algorithm quantizes the fundamental frequency into single note values.

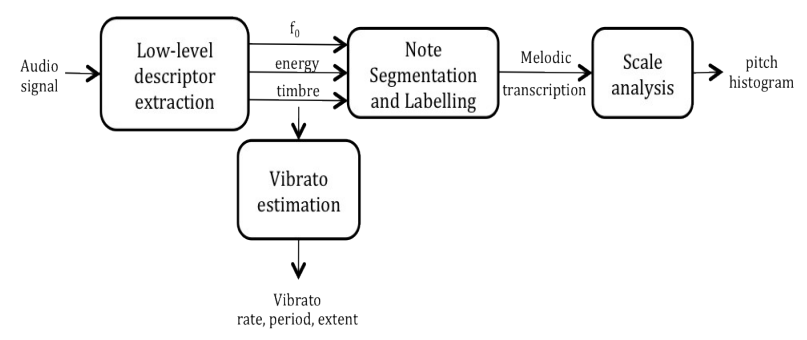

Figure 2. Computational audio analysis scheme

The so obtained symbolic representation is the basis for the computation of pitch histograms, which display the temporal of occurrence of each pitch class wrapped into a single octave. We analyze the pitch histograms regarding the relation between temporal occurrence and tonal importance of the different scale degrees. Based on both, automatic transcriptions and fundamental frequency envelopes, we compute statistical performance descriptors related to pitch content, vibrato and note onsets and dura-

\section{RESULTS AND CONCLUSION}

Analyzing the pitch histograms, we illustrated that the tonal importance of the tonic in the martinete does not correspond to an elevated temporal occurrence, since long melismatic ornamentation and insistence on recitative note are usually limited to scale degrees other than the tonic. The histogram furthermore shows a concentration of the pitch content in the first six scale degrees and a comparatively high temporal occurrence of pitch classes not contained in the underlying scale. In contrast, the temporal pitch distribution of the notes of the inshád does reflect their corresponding tonal importance, is spread more equally over all pitch classes and is mainly limited to the notes contained in the Al-Sika mode. Analyzing fast pitch fluctuations we furthermore observe a simultaneous overlay of melisma and vibrato in the martinete performance.

In this study, we have presented a methodology for the analysis of music recordings that combines manual and automatic descriptions of music recordings by using

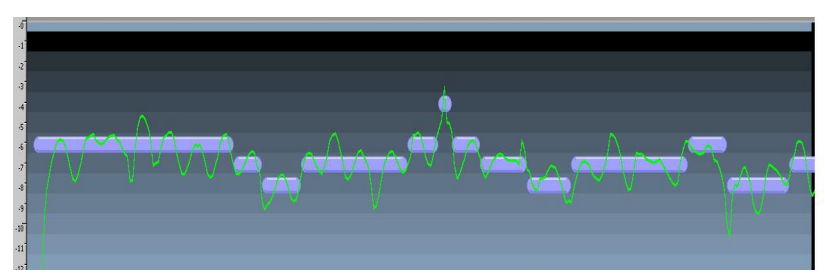

Figure 3. Automatic transcription and fundamental frequency envelope of a martinete excerpt.

state-of-the-art techniques. We detected similarities and differences on the two analyzed pieces, martinete and inshád, in terms of tonality, ornamentation, melodic line, scale, and vibrato. Although these properties refer to specific pieces, some of the traits are representative of flamenco and Arab-Andalusian music traditions. In the future, we intend to carry out a more extensive analysis that will include many pieces of each music tradition. Our methodology can be applied to other pieces and traditions, but proper adaptation should be carried out. 


\section{REFERENCES}

Blas Vega, J. \& Ríos Ruiz, M. (1988). Diccionario enciclopédico ilustrado del flamenco. Madrid: Cinterco.

Chaachoo, A. (2011): La Música Andalusí. Historia, conceptos y teoría musical. Córdoba: Almuzara.

Cortés García, M. (2003): Kinnas al-Haik. Centro de documentación musical de Andalucía.

Gamboa, J. M. (2005): Una historia del flamenco. Madrid: Espasa-Calpe.

Guettat, M. (2000): La musique arabo-andalouse. L'empreinte du Maghreb. El Ouns / Fleurs sociales.

Merchán Higuera, F. (2008): Expressive characterization of flamenco singing. Master thesis. Universitat Pompeu Fabra, Barcelona.

Mora, J., Gòmez, F., Gómez, E., Escobar-Borrego, J. \& DíazBañez, J. M. (2010): Characterization of Melodic Similarity of A Cappella Flamenco Cantes. In Proceedings of the $11^{\text {th }}$ International Society for Music Information Retrieval (ISMIR).

Navarro, J. L. \& Ropero, M (1995): Historia del flamenco. Sevilla: Tartessos.

Poché, C. (1995): La musique arabo-andalouse. Paris: Cité de la Musique / Actes Sud. 